\title{
Assessment of the silicon compounds effect on disease resistance and productivity of spring barley with a decrease in pesticide load in the south of Russia
}

\author{
Irina $V$. Slastya*, Elena $V$. Khudyakova, and Marina $N$. Stepantsevich \\ Russian State Agrarian University - Moscow Agricultural Academynamed after K.A. \\ Timiryazev, 127550 Moscow, Russia
}

\begin{abstract}
In a small-plot field experiment, the effect of different forms of silicon compounds (tetraethoxysilane (TES) and sodium silicate) and processing methods (seeds and plants) on disease incidence and productivity of spring barley varieties was studied and the effect of diseases on productivity was evaluated. It was found that the use of siliconcontaining compounds separately and in a mixture with a reduced consumption rate of fungicide led to a decrease in the infestation of barley with root rot and leaf spots. The lowest degree of disease development was observed when using a fungicide and mixtures of TES and sodium silicate with a reduced consumption rate of fungicide. The maximum yield increases were obtained by combining two types of treatment with silicon seeds and plants. When processing seeds, the use of sodium silicate was more effective. The relationship between the development of diseases and the productivity of spring barley, primarily grain biomass, is estimated in most cases as strong and medium.
\end{abstract}

\section{Introduction}

In recent years, crop losses from harmful organisms remain high, despite the increase in the use of pesticides in agricultural production in many countries. The affection of plants by fungal diseases is one of the main limiting factors that lead to a significant decrease in productivity. In Russia, crop losses from diseases alone range from 6 to 25 million tons of grain per year [1]. In the arid conditions of the Lower Volga region and other regions of southern Russia, leaf helminthosporioses are widely distributed on barley crops, such as net (pathogen - Drechslera teres), dark brown (pathogen - Bipolaris sorokiniana (Sacc.) and less often - stripe (pathogen - Drechslera graminea) spots, rhynchosporium leaf spot, or Rhynchosporium spot (pathogen - Rhynchosporium secalis), as well as root rot - Bipolaris sorokiniana (Sacc.)), powdery mildew (pathogen - Erysiphe graminis $f$. sp. hordei), dwarf rust (pathogen - Puccinia hordei).

The use of traditional chemical plant protection products - pesticides - carries risks of agricultural products and environmental objects contamination, the appearance of resistant

*Corresponding author:slastya2007@mail.ru 
forms of harmful organisms and the death of useful ones. In this regard, an important role is played by techniques aimed at increasing the resistance of cultivated crops to adverse environmental factors. For this purpose, the use of silicon compounds in grain, legumes, vegetable, fruit and berry, and medicinal crops has been studied for many years. It is established that silicon has a positive effect on the growth and productivity of crops, shows adaptogenic properties, increasing the resistance of plants to abiotic and biotic stresses. There is evidence that silicon increases plant resistance to salinization [2-5], moisture deficiency [2, 6-9], lack of illumination [10], fungal diseases [3, 12-16], and pests [11, 12, 16-18]. Among the methods used for the application of silicon compounds, the processing of seed material and the spraying of vegetative plants have lower economic costs and, therefore, a greater prospect.

According to a number of researchers, the greatest effect of silicon compounds is shown in unfavorable weather years. In nature, plants are simultaneously exposed to several adverse environmental factors (biotic and abiotic). In the arid conditions of the south of Russia, fungal infections act against the background of frequent atmospheric and soil droughts. At the same time, in unfavorable weather conditions, the harmfulness of fungal diseases, as a rule, increases. Although there is evidence that the combination of drought and pathogenic infection can have both negative and positive effects on the plant [19]. The outcome of this interaction may depend on the severity of each stress [20].

The results of our field, vegetation and laboratory experiments to study the effect of silicon compounds on the productivity and resistance of spring barley to adverse factors showed that silicon compounds affected the hormonal status of spring barley and contributed to improving plant growth, increasing productivity and resistance to drought. Due to the multidirectional positive effect of silicon on plants, which is manifested in mechanical tissues strengthening that hinder the penetration of fungal infection $[11,12]$, increasing the redox potential of cell juice that slows down the development of fungal hyphae [11], as well as in stimulating the growth of the root system and aboveground mass, changing the balance of endogenous phytohormones and increasing the rate of repair after drought, it was interesting to study not only the effect of silicon compounds on the yield and disease infestation ofbarley under natural conditions, but also to assess the impact of diseases on the productivity of different varieties of barley.

\section{Materials and methods}

The research was carried out in 2005-2007 in the Kamyshinsky district of the Volgograd region on spring barley (Hordeum vulgare L.) of the varieties Kamyshinsky 23, Donetsky 8 and Preriya in the conditions of a small-plot field experiment. The selected varieties differ in drought resistance: the most drought-resistant is the Preriya variety, the least Kamyshinsky 23. The soil of the experimental site is light-loamy chestnut. The content of easily hydrolyzable nitrogen according to Tyurin and Kononova - 46.0, mobile phosphorus $\left(\mathrm{P}_{2} \mathrm{O}_{5}\right)$ according to Machigin - 24.0, exchangeable potassium $\left(\mathrm{K}_{2} \mathrm{O}\right)$ according to Machigin $-210 \mathrm{mg} / \mathrm{kg}$ of soil, $\mathrm{pH}_{\text {water }}-6.7$. In the spring, mineral fertilizers were added to the soil in the form of azophoska (N:P:K=30:30:30). The plot area was $1 \mathrm{~m}^{2}$. The experience was repeated three times.

From the silicon compounds, the ethyl ether of orthosilicic acid - tetraethoxysilane (TES) and sodium silicate at a concentration of $0.4 \%$ were used. TES and sodium silicate were used for seed treatment, and only sodium silicate was used for plant spraying. Seed treatment was carried out at the rate of $12 \mathrm{l} / \mathrm{t}(1.2 \mathrm{ml}$ of solution per $100 \mathrm{~g}$ of seeds). The plants were sprayed during the stem extension phase (beginning of the formation of the 7 th leaf). When processing seeds, sodium silicate and TES were used separately and in a mixture with a systemic fungicide from the class of triazole derivatives - ferrax, $44 \%$ t.a.c. 
at a reduced consumption rate in two times $(1.25 \mathrm{l} / \mathrm{t})$. The total consumption rate of the fungicide was $2.5 \mathrm{1} / \mathrm{t}$. Ferrax has a broad spectrum of action to combat infections transmitted through seeds, soil and air, and has a protective, healing and fumigant effect. It is compatible in tank mixtures with other pesticides. In the control version, the seeds were treated with water.

The experiment scheme included the following options: 1 - control, 2 - fungicide, 3 fungicide $0.5+$ TES (seeds), 4 - fungicide $0.5+$ sodium silicate (seeds), 5 - TES (seeds), 6 - sodium silicate (seeds), 7 - control (seeds) + sodium silicate (plants), 8 - TES (seeds) + sodium silicate (plants), 9 - sodium silicate (seeds + plants).

In recent years, methods based on artificial intelligence and neural networks, which have great prospects, have been used to diagnose the disease of agricultural crops. But their use has not yet become widespread due to a number of problems that have not yet been solved [21]. Therefore, visual methods remain the main methods for assessing the disease infestation of crops. In our studies, the intensity of disease damage to barley was determined twice during the growing season according to the method of A.E. Chumakov and T.I. Zakharova [22]: the degree of leaf spotting was determined in the tillering and milk-ripe phases of the grain, the infestation by root rot - in the germination phase and during the harvesting period. Root rot was determined only in variants 1-6 since the spraying of plants could not have a significant impact on their development.

The years of research varied according to meteorological conditions. The wettest year was 2006, the year 2005 was moderately dry, and the 2007 was the driest year.

Statistical data processing was performed using the programs STRAZ and EXEL 2010. The significance of the correlation coefficients was evaluated according to Dospekhov B.A. [23] using the Student's criterion.

\section{Results and discussion}

In the years of research in the first half of the growing season, all the studied varieties of barley had no signs of root rot and leaf-stem diseases. In the second half of the growing season, the plants were affected by root rot and net spot, and in the wet year 2006 - also by powdery mildew and rhynchosporium leaf spot. The degree of disease development in all varieties in the years of research was low and did not exceed the economic thresholds of harmfulness. The Kamyshinsky 23 variety was more affected by both root rot and leaf-stem diseases. The lowest development of diseases in all studied barley varieties was noted in 2005 , the highest development of leaf spots was observed in the wettest 2006, and root rot in the extremely dry 2007.

Treatment of seeds with silicon compounds on average over the years of research reduced the incidence of root rot in barley by $7-25 \%$ in relation to the control, while sodium silicate acted better than TES, especially on the Preriya and Kamyshinsky 23 varieties, the effect of TES was not reliable in all years. In these varieties, when using only silicon compounds, the degree of root rot development was greater than when using their mixtures with a reduced rate of fungicide consumption, which were not inferior in effect to the full rate of ferrax consumption (Fig. 1). 


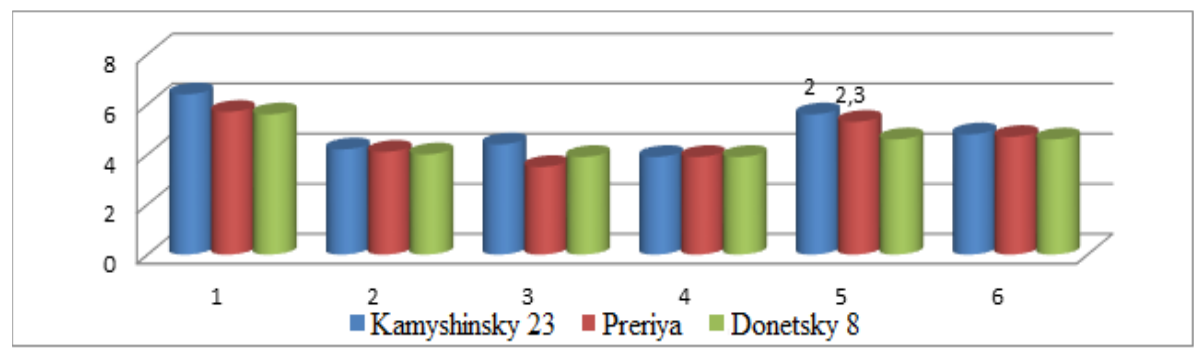

Fig. 1. The degree of spring barley root rot development (\%) in the experimental variants (average over the years of research; the figures above the columns show the years when no significant changes to the control were obtained: 1-2005, 2-2006, 3-2007)

Taking into account the infestation with net spot also showed a significant decrease in the development of the disease in the variants with mixtures of fungicide in a reduced consumption rate with silicon compounds - by $24-32 \%$, comparable to the decrease in the variant with a full rate of fungicide. Sodium silicate and especially TES did not significantly affect the net spot of barley in all years. In the wet year of 2006, neither TES nor sodium silicate had a significant effect on the development of net spot on all three varieties. Spraying plants with sodium silicate reduced the development of net spot on average over the years of research by $14-22 \%$, depending on the variety (the Preriya variety had the greatest responsiveness). When applying spraying to seed treatment, the degree of disease development was lower than in the control by $20-30 \%$, when using a fungicide in the full rate of consumption - by $25-30 \%$. At the same time, double treatment with sodium silicate led to a greater reduction in the net spot of barley than the combination of plant spraying with TES seed treatment (Fig. 2).

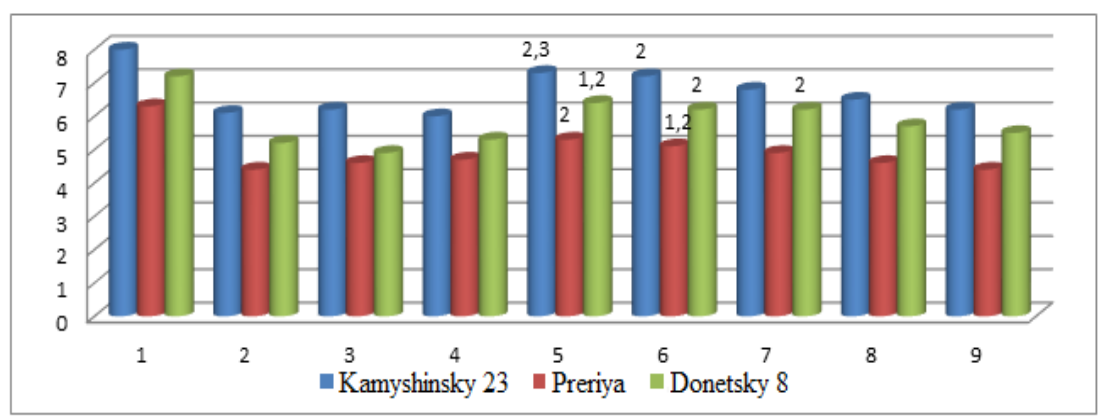

Fig. 2.The degree of spring barley net spot development (\%) in the experimental variants (average over the years of research; the figures above the columns show the years when no significant changes to the control were obtained: 1-2005, 2-2006, 3-2007)

The degree of powdery mildew and rhynchosporium leaf spot development in the variants with the use of mixtures of fungicide with silicon compounds was $22-34 \%$ lower than in the control, with the use of one fungicide $-12-29 \%$. With the independent use of silicon compounds for seed treatment on the Kamyshinsky 23 variety, sodium silicate had an advantage over TES, significantly reducing the degree of development of both powdery mildew and rhynchosporium leaf spot, on the Preriya variety - only powdery mildew. On the Donetsky 8 variety, on the contrary, the treatment of seeds with TES had an advantage in relation to rhynchosporium leaf spot. Spraying plants on all varieties significantly reduced the degree of development of powdery mildew and rhynchosporium leaf spot, especially when used in combination with seed treatment (Fig.3). 


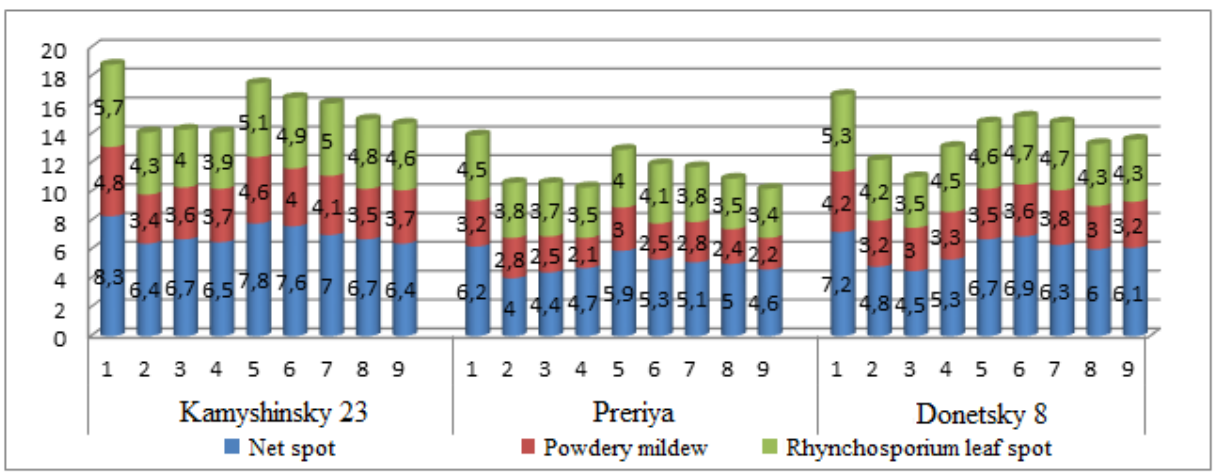

Fig. 3. Degree of leaf spot development (\%) in 2006 (for net spot, $\mathrm{LSD}_{0.95 \mathrm{hr}}=1.0$; for powdery mildew, $\mathrm{LSD}_{0.95} \mathrm{hr}=0.4$; for rhynchosporium leaf spot, $\mathrm{LSD}_{0.95} \mathrm{hr}=0.7$ )

The studied variants of silicon treatment contributed to an increase in the barley productivity. The seed treatment with TES increased the grain biomass on average for three years in the Kamyshinsky 23 variety by $5 \%$, in the Preriya variety - by $9 \%$ and in the Donetsky 8 variety - by $13 \%$ in relation to the control, and in the sodium silicate treatment by 15,10 and $13 \%$, respectively (Fig. 4). The increase in straw biomass in the variants with TES in the varieties was $8-10 \%$ compared to the control, and in the variants with sodium silicate, the straw mass increased only in the varieties Kamyshinsky 23 - by $9 \%$ and Donetsky 8 - by 14\% (Fig. 5). The use of TES mixture with a reduced rate of fungicide consumption by two times increased the grain biomass in the studied varieties by $9-13 \%$, and a mixture with sodium silicate - by $7-11 \%$, respectively. Straw biomass increased in the studied varieties by $7-9$ and $6-14 \%$, respectively.

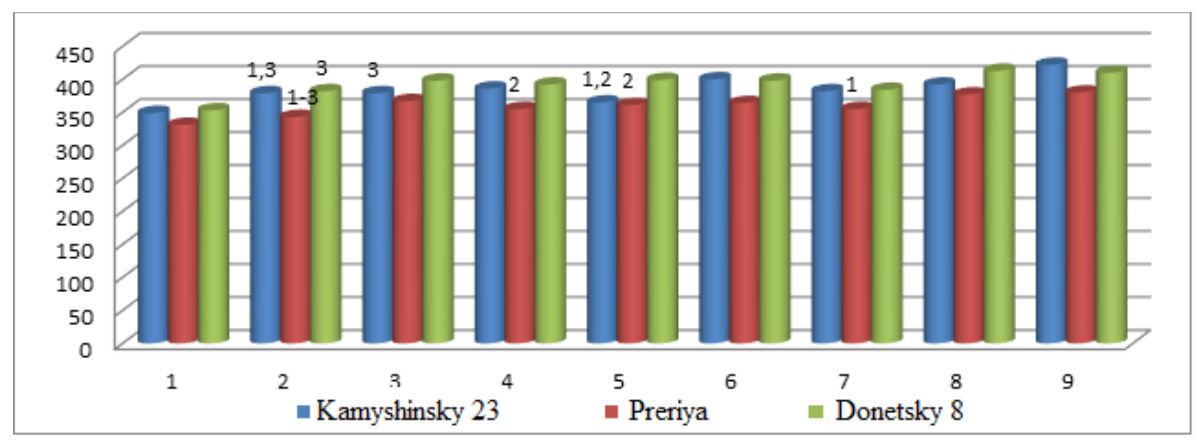

Fig. 4. The spring barley grain biomass $(\mathrm{g} / \mathrm{m} 2)$ in the experimental variants (average over the years of research; the figures above the columns show the years when no significant changes to the control were obtained: 1-2005, 2-2006, 3-2007)

Spraying plants with sodium silicate on all varieties in an average of three years gave approximately the same increase in the biomass of grain and straw-9-10\% in relation to the control. The largest grain increase was obtained in variants with a combination of seed treatment and plant spraying: in the Preriya and Donetsky 8 varieties, it was $14-17 \%$ relative to the control, in the Kamyshinsky 23 variety $23-12 \%$ when applying spraying to the seed treatment with TES and $21 \%$ when applying spraying to the seed treatment with sodium silicate. Thus, over the years of research, the less drought-resistant variety Kamyshinsky 23 showed the greatest responsiveness to the use of silicon compounds, and the more drought-resistant Prepiya variety - less. 


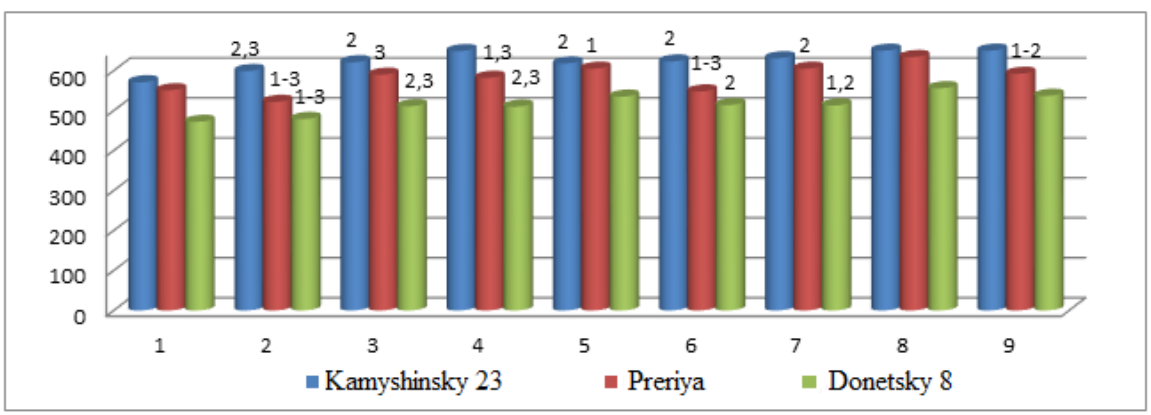

Fig. 5.The spring barley straw biomass $(\mathrm{g} / \mathrm{m} 2)$ in the experimental variants (average over the years of research; the figures above the columns show the years when no significant changes to the control were obtained: 1-2005, 2-2006, 3-2007)

The use of silicon compounds both separately and in a mixture with pesticides contributed to an increase in the total biological productivity by $6-18 \%$, depending on the variety and type of treatment. At the same time, the ratio of grain weight to straw weight increased, which indicates a positive effect of silicon on the regulation of the outflow of assimilates and donor-acceptor relations in the plant.

The use of the fungicide in the full rate of consumption contributed to obtaining reliable grain yield increases in the Kamyshinsky 23 variety only in the wet year 2006, in the Donetsky 8 variety - in 2005 and 2006; no yield increases were obtained in the Preriya variety. Thus, in most cases, with a significant decrease in the degree of root rot and leaf spots development, the grain yield in the variant with the full rate of fungicide consumption did not increase. Consequently, the productivity of barley was largely due to other factors.

To determine the relationship between disease development and productivity of barley, the correlation coefficients between the degree of disease development and the biomass of barley, grain and straw were determined, both in individual years and in aggregate over three years of research, and the significance of the obtained coefficients was evaluated using the Student's criterion (Table 1).

Table 1. Correlation coefficients between the degree of disease development and productivity of spring barley varieties

\begin{tabular}{|c|c|c|c|c|c|c|c|c|c|c|}
\hline \multirow{3}{*}{$\begin{array}{l}\text { Diseases } \\
\text { of barley }\end{array}$} & \multirow{3}{*}{$\begin{array}{l}\text { Observati- } \\
\text { on period }\end{array}$} & \multicolumn{9}{|c|}{ Biomass } \\
\hline & & \multicolumn{3}{|c|}{ Kamyshinsky 23} & \multicolumn{3}{|c|}{ Preriya } & \multicolumn{3}{|c|}{ Donetsky 8} \\
\hline & & of plants & $\begin{array}{c}\text { of } \\
\text { grain }\end{array}$ & of straw & of plants & $\begin{array}{c}\text { of } \\
\text { grain }\end{array}$ & of straw & of plants & $\begin{array}{c}\text { of } \\
\text { grain }\end{array}$ & of straw \\
\hline \multirow[t]{4}{*}{ Root rot } & 2005 & -0.75 & -0.73 & -0.68 & -0.44 & -0.61 & -0.21 & -0.63 & -0.65 & -0.59 \\
\hline & 2006 & -0.88 & -0.93 & -0.62 & -0.24 & -0.55 & -0.10 & -0.28 & -0.61 & -0.28 \\
\hline & 2007 & -0.62 & -0.28 & -0.75 & -0.03 & -0.46 & +0.07 & -0.51 & -0.79 & -0.34 \\
\hline & $\begin{array}{l}\text { for three } \\
\text { years }\end{array}$ & -0.85 & -0.80 & -0.78 & -0.29 & -0.59 & -0.13 & -0.52 & -0.71 & -0.33 \\
\hline \multirow[t]{4}{*}{ Net spot } & 2005 & -0.60 & -0.52 & -0.52 & -0.54 & -0.61 & -0.37 & -0.68 & -0.67 & -0.66 \\
\hline & 2006 & -0.83 & -0.79 & -0.72 & -0.04 & -0.49 & +0.12 & +0.02 & -0.28 & +0.20 \\
\hline & 2007 & -0.34 & -0.12 & -0.45 & -0.46 & -0.78 & -0.40 & -0.32 & -0.61 & -0.19 \\
\hline & $\begin{array}{l}\text { for three } \\
\text { years }\end{array}$ & -0.33 & -0.54 & -0.18 & -0.46 & -0.69 & -0.24 & -0.38 & -0.50 & -0.24 \\
\hline $\begin{array}{l}\text { Powdery } \\
\text { mildew }\end{array}$ & 2006 & -0.80 & -0.61 & -0.76 & -0.47 & -0.75 & -0.29 & -0.58 & -0.82 & -0.41 \\
\hline $\begin{array}{l}\text { Rhyncho- } \\
\text { sporium } \\
\text { leaf spot }\end{array}$ & 2006 & -0.55 & -0.44 & -0.54 & -0.64 & -0.75 & -0.48 & -0.35 & -0.60 & -0.17 \\
\hline
\end{tabular}

For powdery mildew and rhynchosporium leaf spot, the correlation coefficients for all three varieties were also calculated to increase the number of pairs of observations. Only 
the correlation coefficient between the degree of powdery mildew development and the grain biomass was significant (-0.41).

The results showed that the strongest relationship between the root rot development and the grain biomass in the varieties Kamyshinsky 23 and Donetsky 8, the average - in the Preriya variety. A strong relationship was established for the total plant biomass and straw biomass of the Kamyshinsky 23 variety, and the average - for the total biomass of the Donetsky 8 variety. The degree of close connection between the development of net spot and the grain mass is average for all varieties. And for the Kamyshinsky 23 variety in the wet year of 2006, a strong degree of connection with the weight of grain, straw and overall productivity was established. A strong relationship between the powdery mildew development and grain biomass was established for the Preriya and Donetsky 8 varieties, and it is average $(-0.41)$ for the aggregate of the three varieties. A strong degree of connection is also established between the powdery mildew development on the Kamyshinsky 23 variety and its straw weight and overall productivity. For rhynchosporium, a strong degree of connection is established only with grain weight of the Preriya variety.

Thus, diseases, even with a low level of plant damage, largely determined the productivity of the studied barley varieties, and to a greater extent - the Kamyshinsky 23 variety, which showed the greatest responsiveness to the use of silicon compounds, especially sodium silicate.

The lack of yield increase during processing with the full rate of ferrax consumption is probably due to the phytotoxic effect of the fungicide, which could be most strongly manifested in conditions of moisture deficiency: in our studies, the highest efficiency of ferrax was in the wet year 2006, the lowest - in the dry 2007. Therefore, the increase in barley productivity with the use of silicon compounds is associated not only with a decrease in the incidence of diseases of barley, but also with the stimulating effect on plants, the adaptogenic effect of silicon against drought, including through the regulation of the balance of endogenous phytohormones [6].

\section{Conclusions}

1. Silicon compounds, both when processing seeds and when spraying vegetative plants, reduced the degree of root rot and leaf-stem diseases development in barley. During seed treatment, the use of sodium silicate was more effective, especially on the Kamyshinsky 23 variety, which is more affected by diseases.

2. The lowest degree of disease development was observed when using a ferrax and mixtures of TES and sodium silicate with a reduced consumption rate of fungicide.

3. The maximum yield increases were obtained by combining two types of treatment with silicon compounds - seeds and plants. The variety Kamyshinsky 23 was the most responsive to the use of silicon compounds, especially sodium silicate.

4. The use of the fungicide in the full rate of consumption contributed to obtaining reliable grain yield increases in the Kamyshinsky 23 variety only in the wet year 2006, in the Donetsky 8 variety - in 2005 and 2006; no yield increases were obtained in the Preriya variety.

5. The relationship degree between the development of diseases and the productivity of spring barley, primarily grain, is estimated in most cases as strong and medium. The greatest number of strong relations was established for the Kamyshinsky 23 variety. 


\section{References}

1. S.S. Sanin, E.A. Sokolov, V.N. Cherkashin et al, Diseases of grain crops, 140 (2010)

2. I.V. Vernichenko, L.V. Osipova, P.A. Yakovlev, I.A. Bykovskaya, V.A. Litvinsky, $15 \mathrm{~N}$ labeled nitrate nitrogen by plants under stressful growing condition,3, 10 (2017).

3. M.C.H. Chanchal, K. RitiThapar, G. Deepak, Sci. Agricult,13(2), 59 (2016)

4. Sattar, Abdul, et al, Grassland Science, 62(4), 262 (2016)

5. B. Ahmad, Journal of Integrative Agriculture, 13 (2014)

6. I.V. Slastya, V.N. Lozhnikova, V.V. Kondratieva, N.T. Nilovskaya, The effect of water stress and silicon compounds on the content of endogenous phytohormones and the growth of spring barley, $\mathbf{8}, 38$ (2013)

7. G.P. Pushkina, N.I. Sidelnikov, New and non-traditional plants and prospects for their use, 12, 249 (2016)

8. M. Ahmad, M.H. El-Saeid, M.A. Akram, H.R. Ahmad, H. Haroon, A. Hussain, Journal of Plant Nutrition, 39(9), 1283(2016)

9. K. Maghsoudi, Y. Emam, \& M. Pessarakli. Journal of Plant Nutrition, 39(7), 1001 (2016)

10. S. Hussain, L. Shuxian, M. Mumtaz, I. Shafiq, N. Iqbal, M. Brestic, M. Shoaib, Q. Sisi, W. Li, X. Mei,et al, Journal of Hazardous Materials, 401, 23256 (2021)

11. S. Yoshida, Food Fert. Tech. Centr. Tech. Bull. Taipei,4, 28(1975)

12. N.E. Aleshin, Vestn. s. - kh. Nauki,10, 77 (1988)

13. A.V. Kozlov, I.B. Uromova, E.A. Frolov, K.Yu. Mozoleva, International Student Scientific Bulletin,(1), 39(2015)

14. A.Kh. Kulikova, Bulletin of the Ulyanovsk State Agricultural Academy,4(24), 17 (2013)

15. M. Wafaa, Haggag, M. G. Farhat,S.Thabet, Marianetal, Bioscienceresearch, 15(4), 3524

16. W. Islam, M.Tayyab,F. Khalil, Zh.Hua, Zh.Huang, Y.H. Han, Chen, 168(2020)

17. A.Kh. Kulikova, Coll. of proc. of the V International Scientific and Practical Conference "Agricultural Science and Education at the present stage of development: experience, problems and solutions", 42 (2013)

18. S.L. Los, E.V. Borzdyko, L.N. Anishchenko, F.V. Prokhorenko, Coll. «Applied and Fundamental Studies. Proceedings of the $13^{\text {th }}$ International Academic Conference, 11 (2017)

19. V. Ramegowda,M. Senthil-Kumar, Journal of plant physiology,176,47 (2015)

20. E.A. Achuo, E. Prinsen, M. Höfte, Plant Pathol 55, 178(2006)

21. E. V. Khudyakova, I. V. Slastya, V. S. Semenyuk, The Challenge of Sustainability in Agricultural Systems, 2, 805 (2021)

22. A.E. Chumakov, T.I. Zakharova, The harmfulness of diseases of agricultural crops, 127 (1990)

23. B.A. Dospekhov,Methodology of field experience (with the basics of statistical processing of research results), 351 (1985) 